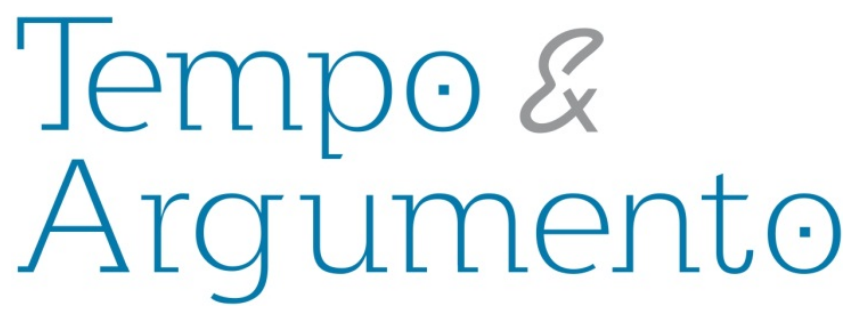

\title{
Os arquivos da segunda guerra mundial na França, da história à história de si
}

\begin{abstract}
Resumo
A abertura ao público dos arquivos da segunda guerra mundial nos anos 1990 constituiu um episódio marcante e por vezes conflituoso da história recente dos arquivos na França. O período foi marcado, com efeito, por uma série de calorosos debates, por vezes polêmicos, sobre as condições jurídicas do acesso a esses documentos. Voltamos aqui a esses anos difíceis, esforçando-nos por decifrar o que eles puderam significar em termos de relação entre leitor e documento de arquivos. Atrás de uma evidente necessidade de história e de uma problemática de memória social e coletiva que não poderiam ser negadas, esconde-se uma assaz profunda transformação das lógicas de uso do documento de arquivos.
\end{abstract}

Palavras-chave: História. Arquivo. Memória. Segunda guerra mundial. Judeus.
Patrice Marcilloux

Professor pesquisador em arquivística da Universidade de Angers - França.

patrice.marcilloux@laposte.net

\section{Tradução}

Fernando Coelho

Mestre em Estudos da Tradução e doutorando em Linguística na

Universidade Federal de Santa Catarina zeffiretto@gmail.com

\section{Para citar este artigo:}

MARCILLOUX, Patrice. Os arquivos da segunda guerra mundial na França, da história à

história de si. Revista Tempo e Argumento, Florianópolis, v. 5, n.9, jan./jun. 2013. p. 312 - 335. 


\title{
The second world war archives in France, from history to one's own history
}

\begin{abstract}
The public opening of the archives of the Second World War in the 1990s was a remarkable and sometimes conflicted episode in the recent history of archives in France. The period was marked, in effect, by a series of heated and sometimes controversial debates on the juridical conditions for the access to these documents. Here we return to these difficult years, striving to decipher what they could have meant in terms of the relationship between reader and archive documents. Behind an obvious need for history and a problematic social and collective memory that could not be denied, hides a very profound transformation of the logic of use of archive documents.
\end{abstract}

Keywords: History. Archive. Memory. Second world war. Jews.

As condições da abertura dos arquivos da segunda guerra mundial aos historiadores profissionais ou amadores e ao grande público nos anos 1990 constituem uma das páginas talvez mais marcantes da história recente dos arquivos na França. $\mathrm{O}$ episódio resultou numa revisão da legislação arquivística em vigor com o empreendimento, em 1996, de um projeto de lei para modificar a lei de 3 de janeiro de 
1979, que terminaria somente em 2008. ${ }^{1}$ Ele revelou também uma intensificação da demanda social dirigida à administração dos arquivos, num clima de tensões e mesmo de polêmicas, que os arquivistas vivenciaram como injustos questionamentos. Sem ousar ainda traçar aqui uma história completa deste período, a qual está por fazer², gostaríamos de chamar a atenção para um aspecto menos conhecido e contudo fundamental a nosso ver deste momento singular no qual um grande número de observadores não hesitou em desvelar os sintomas de uma verdadeira "crise dos arquivos" 3 : a individualização progressiva da relação com os arquivos no pano de fundo da relativização de seu uso histórico, uma passagem da história à história de si, de algum modo. A célebre questão dita da pasta judia e a questão da indenização das espoliações dos judeus da França nos servirão de prisma revelador desta utilização diferente dos arquivos, misturando a grande e a pequena história, a compreensão histórica do passado e as estratégias familiares. Não se poderia, contudo, empreender esta tarefa sem lembrar brevemente, em um primeiro momento, o quadro regulamentar em vigor na década de 1990, nem sem descrever sumariamente os documentos que estão na sua origem.

\section{Documentos e comunicabilidade legal}

No início dos anos 1990, cinquenta anos após o início da segunda guerra mundial, a comunicação dos arquivos aos diferentes públicos que desejavam ter acesso a eles estava legalmente fixada pela lei de 3 de janeiro de 1979, com um decreto de 3 de dezembro de 1979 regulamentando algumas disposições da lei. A análise rápida deste regime jurídico, que não diz respeito senão aos arquivos aos quais a lei reconhece o caráter de arquivos públicos, leva a constatar ao mesmo tempo que muitos documentos relativos à segunda guerra mundial ainda não são comunicáveis, que, graças ao sistema

\footnotetext{
${ }^{1}$ BÉLAVAL (Philippe), «Archives et République », Le Débat, 2001, n 115, p. 100-117 e « Les enjeux de la réforme de la loi de 1979 ", em CORNU (Marie), FROMAGEAU (Jérôme), sob a dir., Archives et recherche, aspects juridiques et pratiques administratives, Paris, L'Harmattan, 2003, p. 9-19.

${ }^{2}$ DUCLERT (Vincent), «Les enjeux de la politique des archives en France », em POIRRIER (Philippe), LAUVERNIER (Julie), sob a dir., Historiographie et archivistique. Écriture et méthodes de l'histoire à l'aune de la mise en archives, Territoires contemporains, nouvelle série, $\mathrm{n}^{\circ} 2$.

${ }^{3}$ DUCLERT (Vincent), "Les historiens et la crise des archives », Revue d'histoire moderne et contemporaine, 2001, n 48 , p. 16-43.
} 
das dispensas, a pesquisa histórica não conhece verdadeiros obstáculos ao seu desenvolvimento, mas, ao mesmo tempo, que, se o equilíbrio definido pelo direito positivo permite prover às necessidades históricas, ele já não chega a satisfazer o conjunto das demandas dirigidas ao sistema arquivístico por todos os usuários.

\section{A lei e o decreto}

Aprovada no contexto de transparência administrativa instaurado pela lei de 17 de julho de 1978 sobre a liberdade de acesso aos documentos administrativos e pela lei de 6 de janeiro de 1978 relativa à informática, às pastas e às liberdades, reputava-se que a lei de 1979 sobre os arquivos tinha instaurado, até o início dos anos 1990, um regime "muito liberal" ${ }^{4}$ de comunicação dos arquivos públicos. Reunindo, uniformizando e completando disposições até então esparsas e de origem com frequência simplesmente regulamentar, ela prevê que todos os documentos livremente comunicáveis antes de sua entrada nos arquivos permaneçam assim, e que os outros tenham um prazo comum de trinta anos. Os documentos mais confidenciais são exceção e são regidos por prazos especiais, no número de cinco e variando entre sessenta e cento e cinquenta anos.

Os arquivos da segunda guerra mundial são regidos principalmente por dois desses prazos. Um prazo de sessenta anos a contar da data do ato toca aos documentos que contêm informações que versam sobre a vida privada ou que são de interesse para a segurança do Estado ou a defesa nacional e cuja lista é fixada pelo decreto de 3 de dezembro de 1979. Ainda que o decreto Jobez, do Conselho de Estado, tenha limitado, em 1994, o alcance do decreto no que diz repeito à noção de segurança do Estado, a prática arquivística corrente continua a considerar que a presença de uma categoria de documentos na lista dada pelo decreto de 3 de dezembro de 1979 basta ipso facto a submeter ao prazo de 60 anos $^{5}$. Um prazo de cem anos a contar da data do ato ou do

\footnotetext{
${ }^{4}$ PONTIER (Jean-Marie), RICCI (Jean-Claude), BOURDON (Jacques), Droit de la culture, Paris, Dalloz, $1990, \mathrm{p}$. 338.

${ }^{5}$ BASTIEN (Hervé), Droit des archives, Paris, La Documentation française, 1996, p. 96-97.
} 
fechamento do dossiê incide sobre os documentos relativos às questões levadas às jurisdições, incluindo-se as decisões de graça.

Sobretudo, retomando uma tradição instaurada desde o século XIX, a lei de 1979 instaura um regime de dispensas em virtude do qual os documentos submetidos ao prazo de trinta anos e aos prazos especiais podem beneficiar-se de uma consulta antecipada, antes da expiração desses prazos, por decisão do diretor dos Arquivos da França, que estatui após concordância da administração que depositou os documentos. Embora a lei tenha previsto dispensas individuais e gerais, a prática arquivística favorece claramente as dispensas individuais que, tendo a vantagem de permitir assaz facilmente as pesquisas de caráter histórico, apresentam porém o inconveniente de nutrir desconfiança relativamente aos arquivistas suspeitos de arbitrariedade na percepção da natureza das demandas e de suas motivações ${ }^{6}$. Mesmo o favor tradicionalmente conferido aos pedidos de dispensa orientados à produção de uma pesquisa histórica, imbuída das melhores intenções, pode causar problemas e ser interpretada pelo viés do elitismo do fechamento. A circular dita Jospin, de 2 de outubro de 1997, relativa ao acesso aos arquivos públicos do período de 1940 a 1945, reafirma este ponto de vista, mas numa preocupação de abertura: “As dispensas deverão ser amplamente concedidas para efetuar pesquisas históricas, em particular aos membros da comunidade científica ou universitária (pesquisadores e professores), quer sejam franceses, quer estrangeiros. $\mathrm{O}$ mesmo se fará para os estudantes do ensino superior que apresentem pedidos para a conclusão de uma monografia ou de uma tese."7

\section{Os documentos de arquivos}

$\mathrm{Na}$ aplicação dessas disposições legais e regulamentares se acham, portanto, excluídas de uma livre comunicação imediata neste início dos anos 1990 numerosos documentos de um interesse certo tanto para a escrita da história da segunda guerra

\footnotetext{
${ }^{6}$ COMBE (Sonia), Archives interdites : les peurs françaises face à l'histoire contemporaine, Paris, Albin Michel, 1994, $328 \mathrm{p}$.

7 Journal officiel de la République française, 3 de outubro de 1997, p. 14340.
} 
mundial, quanto para as pesquisas de caráter genealógico ou familiar. Os decretos de dispensa geral que seriam finalmente baixados em 1999 e 2002 testemunham isto eloquentemente, embora parcialmente. ${ }^{8}$ Para nos concentrarmos apenas nos arquivos dos departamentos (decreto de 29 de abril de 2002 publicado no Diário Oficial de 3 de maio de 2002), são principalmente os relatórios periódicos dos governadores e dos vicegovernadores, os relatórios de polícia e informações gerais, alguns dossiês de gabinetes de governadores, sobretudo os relativos à supervisão das organizações políticas e sindicais ou à organização dos campos de internamento e dos comboios de deportação, os arquivos dos campos de internamento, os documentos de caráter nominativo emanados do Serviço do trabalho obrigatório, todos documentos para os quais o prazo é de sessenta anos. Aos Arquivos Nacionais, são em particular os arquivos de numerosos serviços que dependem do Ministério do Interior ou depositados pelo Ministério dos Excombatentes (decreto de 11 de outubro de 1999 publicado no Diário Oficial de 17 de novembro de 1999 e decreto de 15 de abril de 1999 publicado no Diário Oficial de 13 de maio de 1999): gabinete do ministro, Segurança Nacional, informações gerais, supervisão dos partidos e movimentos, inspeção dos campos, fichas de polícia, fichas dos campos. É preciso acrescentar aqui todos os arquivos provenientes das jurisdições, e sobretudo os arquivos das cortes de justiça criadas em 1944 com vistas ao expurgo dos colaboradores, os quais deviam permanecer ao largo dos decretos de dispensa geral do fim dos anos 1990 e do início dos anos 2000, em razão do prazo de comunicabilidade fixado em cem anos.

\section{O pedido}

As cifras publicadas pela direção dos Arquivos da França no seu relatório anual de atividade mostram primeiramente um forte crescimento do número dos pedidos de dispensa, globalmente considerados: 482 pedidos em 1985, 988 em 1990, 3.184 em 2001,

\footnotetext{
${ }^{8}$ Para uma visão de conjunto : BLANC (Brigitte), ROUSSO (Henri), TOURTIER-BONAZZI (Chantal de), sob a dir., La seconde guerre mondiale. Guide des sources conservées en France. 1939-1945, Paris, La

Documentation française, 1994, 1218 p.
} 
ou seja, uma multiplicação por mais de 6 em 15 anos. Embora este crescimento deva ser posto em relação com o aumento muito sensível da frequentação dos arquivos nacionais e departamentais, o qual é multiplicado por três nos mesmos anos, é difícil não ver nesses elementos estatísticos o sinal senão de um novo questionamento do regime legal da comunicabilidade, pelo menos de uma pressão exercida sobre ele e como um indício de sua inadequação.

A divisão desses pedidos em períodos mostra a esmagadora predominância da segunda guerra mundial: 1.019 pedidos acerca da segunda guerra mundial em 2001, ou seja, $32 \%$ de todos os pedidos de dispensa feitos naquele ano. Depois do decreto de 2002, o qual levou à abertura por dispensa geral dos arquivos dos serviços descentralizados do Ministério do Interior, a parte das dispensas ligadas à segunda guerra mundial diminui mas se estabiliza em um nível significativo: 20\% em 2002, 14\% em 2003, 18\% em 2005, 14\% em 2006, 15\% em 2007. Entre 2005 e 2007, os redatores do relatório anual da direção dos Arquivos da França notam com constância que "este período suscita sempre muitos pedidos de dispensa" ${ }^{9}$. A classificação dos pedidos segundo sua natureza é igualmente rica de ensinamentos, ainda que se tenha que ter cuidado com os dados, uma vez que são tributários ao mesmo tempo da percepção da natureza do seu pedido pelo requerente no momento em que preenche o formulário oficial da inscrição em um serviço de arquivos e dos eventuais corretivos feitos pela direção dos Arquivos da França. Nota-se, contudo, que, ainda em 2002, ou seja, após a publicação dos decretos de dispensa geral, $27 \%$ dos pedidos são para "pesquisas históricas pessoais" ou apresentam um caráter “genealógico", enquanto $71 \%$ dizem respeito a "pesquisas científicas", segundo a terminologia empregada pela administração central dos arquivos. Em 2006, o relatório anual constata pela primeira vez a propósito dos pedidos de dispensa para os arquivos da segunda guerra mundial que "os pedidos feitos com fins de pesquisa universitária já não constituem a maioria" e que 57\% dentre eles "emanam de pessoas desejosas de consultar

\footnotetext{
${ }^{9}$ Des archives en France, l'activité de la direction des Archives de France et des services publics d'archives, 2005, p. 64 ; Des archives en France, l'activité de la direction des Archives de France et des services publics d'archives, 2006, p. 98 ; Des archives en France, l'activité de la direction des Archives de France et des services publics d'archives, 2007, p. 103.
} 
arquivos de jurisdição seja para melhor conhecer o percurso de um de seus ascendentes condenado durante a Ocupação ou no momento da depuração, seja, numa menor proporção, para conduzir, individual ou associativamente, pesquisas sobre a Resistência e a Colaboração"10.

\section{Pasta judia e CIVE: uma aparente necessidade de história}

Dois livros ${ }^{11}$, uns trinta artigos num jornal como Le Monde, milhares de páginas na internet, a questão da pasta judia exprimiu entre 1991 e 1997 num paroxismo a tomada de consciência por parte do grande público da responsabilidade do Estado francês na perseguição dos judeus da França durante a segunda guerra mundial. Ela lança luz também na complexidade da relação entre arquivos, história, memória, sociedade e usos individuais. Criada pelo decreto do Primeiro Ministro em 10 de setembro de 1999, a Comissão para a Indenização das Vítimas de Espoliações realizadas em razão das legislações antissemitas em vigor durante a Ocupação (CIVE) tem efeito na prática. Aqui, a necessidade de história não é primeira; ela resulta de uma soma de demandas individuais de caráter inicialmente jurídico e financeiro.

\section{A questão da pasta judia: balizas cronológicas}

No dia 13 de novembro de 1991, um artigo do jornal Le Monde revela que Serge Klarsfeld, advogado de algumas partes civis no processo crime contra a humanidade aberto por contumácia na corte de Paris contra Aloïs Brunner, chefe do campo de Drancy, acaba de encontrar a "pasta dos judeus", que se acreditava perdida ou destruída, e que ele pretende pedir o confisco ao juiz de instrução encarregado. Segundo este artigo, a pasta encontrada nos serviços da Secretaria de Estado no Ministério dos Ex-combatentes é exatamente a grande pasta dos judeus do departamento de polícia de Paris, ou seja, a

\footnotetext{
${ }^{10}$ Des archives en France, l'activité de la direction des Archives de France et des services publics d'archives, 2006, p. 99.

${ }^{11}$ Além de Sonia Combe, KAHN (Annette), Le Fichier, Paris, Robert Laffont, 1993, XX-235 p.
} 
pasta de recenseamento geral da população judia da zona ocupada, criada pela aplicação das instruções da administração militar alemã de 27 de setembro de 1940 e confeccionada por declarações individuais nas delegacias de polícia em outubro de 1940. Nas semanas que se seguem, a polêmica cresce rapidamente por uma série de razões. Primeiro, esta pasta se reveste, no plano memorial, de uma importância particular: é graças a ela que as pilhagens e deportações do Vélodrome do inverno de 1942 puderam acontecer em condições de eficácia administrativa certa. Interrogado várias vezes sobre a sorte desta pasta reputada destruída, o Ministério dos Ex-combatentes sempre havia afirmado não a possuir. Enfim, vimos a saber muito rapidamente que esta pasta, conservada pelo escritório dos arquivos da subdireção da regulamentação e dos estatutos, havia conservado uma utilidade administrativa servindo à instrução dos pedidos de pensão ou de títulos de judeus deportados. Este exemplo emblemático de uma utilização administrativa prolongada de documentos já revestidos de um valor histórico desperta uma grande indignação: “agindo assim (ou seja, servindo-se desta pasta), o Ministério dos Ex-combatentes assumia uma classificação dos cidadãos realizada por um regime não democrático. Voltou-se esta pasta contra as suas vítimas porque não confiava nelas, preferindo-se referir ao trabalho de seus carrascos. Ao sabê-lo, senti um amargor", declara o historiador Marc Ferro ${ }^{12}$. Não cabe aqui retraçar todos os desenvolvimentos desta questão, que devia terminar no dia 5 de dezembro de 1997, com o depósito da pasta judia no Memorial do Mártir Judeu Desconhecido, na presença de Jacques Chirac ${ }^{13}$. Gostaríamos, por outro lado, de sublinhar certo número de pontos que relativizam a análise da sequência sob o prisma exclusivo da polêmica memorial e da necessidade de história.

\footnotetext{
${ }^{12}$ Le Monde, 16 de novembro de 1991.

${ }^{13}$ Para uma visão de conjunto: JOINET (Louis), « Affaire dite du "Fichier des Juifs" », Le Monde juif, abriljunho de 1991, n 142, p. 84-105; POZNANSKI (Renée), « Le fichage des Juifs de France pendant la Seconde Guerre mondiale et l'affaire du fichier juif », La Gazette des archives, 1997, $\mathrm{n}^{\text {os }} 177-178$, p. 250270 ; JOLY (Laurent), L'Antisémitisme de bureau. Enquête au cœur de la préfecture de Police de Paris et du commissariat général aux Questions juives (1940-1944), Paris, Grasset, 2011, p. 316-345. Sobre a origem da pasta : GRAND (Philippe), « Le Fichier juif : un malaise (réponse au rapport Rémond remis au Premier ministre le 3 juillet 1996) ", Revue d'histoire de la Shoah, 1999, n¹67, p. 53-101; AZÉMA (Jean-Pierre), « Le "fichier juif" : réponse à Philippe Grand ", Revue d'histoire de la Shoah, 2000, n¹69, p. 249-256.
} 


\section{Invisibilidade dos arquivistas, derrota dos historiadores?}

Ao longo da questão, os arquivistas tiveram a desagradável impressão de ser incompreendidos e inaudíveis e de não ter acesso às mídias, obrigados a confiar sua defesa a historiadores que ocupavam o proscênio. O lugar e o papel desses últimos não devem ser, por isso, superestimados. Certamente, alguns historiadores se exprimem regularmente na imprensa e nas rádios: René Rémond, Marc Ferro, Jean-Pierre Azéma, François Bédarida, Henry Rousso, Pierre Vidal-Naquet, André Kaspi. Certamente, é a uma comissão presidida pelo historiador René Rémond, aliás presidente do Conselho Superior dos Arquivos, a quem o ministro da Cultura, Jack Lang, confia no dia 7 de abril de 1992 a tarefa de estudar a factibilidade jurídica do depósito revocável da pasta no Memorial do Mártir Judeu Desconhecido (atual Memorial da Shoá) preconizado precedentemente pela Comissão Nacional da Informática e das Liberdades. Composta de dois outros historiadores, Jean-Pierre Azéma e André Kaspi, de uma arquivista (Chantal de TourtierBonazzi, conservadora da seção contemporânea) e do presidente do Conselho Representativo das Instituições Judias da França (Jean Kahn), a comissão recomenda em seu relatório definitivo enviado ao Ministro no dia 3 de julho de 1996 a conservação da pasta nos Arquivos Nacionais, em conformidade com a regulamentação, em salas particulares, formando um lugar de memória. Um microfilme seria enviado ao Centro de Documentação Judia Contemporânea, enquanto algumas fichas seriam expostas no Memorial Judeu. Mas ela não foi seguida: desde o dia 6 de julho de 1996, Serge Karsfeld acusa a comissão Rémond, em um artigo publicado pelo Le Monde, de ter sido formada com o objetivo de permitir aos Arquivos Nacionais conservar esta pasta e pede ao governo que não siga o parecer da comissão sobre o depósito da pasta nos Arquivos Nacionais, considerando que a Shoá, da qual faz parte o recenseamento de 1940, transcende o aspecto nacional pela excepcionalidade de uma tragédia que engloba os judeus da Europa, massacrados não enquanto cidadãos de seus respectivos países, mas pelo crime de terem nascido judeus. É esta opinião que prevalece rapidamente, contra os historiadores e os arquivistas, e que o presidente da República anuncia querer seguir no dia 12 de outubro de 1996. É em vão que Jean-Pierre Azéma, François Bédarida e Henry Rousso publicam no dia 16 de novembro de 1996 um artigo no Le monde para denunciar o 
fato de que o presidente da República "aceita que o patrimônio histórico da nação, e em particular o das horas mais sóbrias, cessa de ser nacional”. E por medo de que os descendentes dos vendéens blancs reclamem a transferência para Cholet dos documentos relativos às colônias infernais, ou que o Museu do Deserto exija os arquivos dos camisards perseguidos em razão de sua fé e pelos exércitos do rei.

Mais surpreendente, as conclusões da comissão são contestadas, inclusive no plano da análise histórica, onde a sua composição deveria ter sido suficiente para lhe assegurar um tipo de infalibilidade admitida por todos. Desde o dia 28 de dezembro de 1992, René Rémond endereça ao ministro da Cultura um breve relatório parcial que afirma de maneira peremptória que a pasta descoberta na Secretaria de Estado no Ministério dos Ex-combatentes não é a pasta geral do recenseamento dos judeus, saída da ordenança das autoridades de ocupação do dia 27 de setembro de 1940: "Estimamos, portanto, que estamos em condições de afirmar que a pasta cuja suposta descoberta suscitou uma forte emoção foi destruída, o que torna parcialmente sem objeto uma parte da controvérsia." Esta tese é imediatamente contradita com veemência por Serge Klarsfeld. Pôde-se analisar a polêmica como o antagonismo de duas posturas, a "postura elitista”, do “'saber histórico' contra as abordagens militantes", em face da "postura militante", a da "defesa da 'verdade' contra 'a história oficial”"14. É verdade que Serge Klarsfeld reclamou várias vezes de ter tido que, mais do que qualquer outro historiador, multiplicar as estratégias para contornar as dificuldades de acesso aos arquivos administrativos "oficiais" 15 . Mas há mais. Duas concepções dos arquivos se opõem e são difíceis de compreender, a daqueles que têm primeiramente como função elaborar sistemas explicativos do passado e aquela cuja obra principal reside na reconstituição paciente das listas de deportados: um memorial ${ }^{16}$. No prefácio que escreveu para o livro de Annette Kahn, Serge Klarsfeld qualifica as recusas de comunicação da pasta de Drancy por parte do Ministério dos Ex-combatentes de faltas não somente em relação às

\footnotetext{
14 JOLY (Laurent), L'Antisémitisme de bureau. Enquête au cœur de la préfecture de Police de Paris et du commissariat général aux Questions juives (1940-1944), Paris, Grasset, 2011, p. 336-343.

15 « Le fichier juif. Table ronde », La Gazette des archives, 1997, $n^{\text {os }}$ 177-178, p. 241-249.

${ }^{16}$ Le Mémorial de la déportation des Juifs de France : listes alphabétiques par convois des Juifs déportés de France, historique des convois de déportation, statistiques de la déportation des Juifs de France, 1978.
} 
necessidades da pesquisa histórica, mas também “em relação à psicologia da comunidade judia": "Qual é o filho de deportado que não gostaria de dispor de uma fotocópia da ficha de seu pai, de sua mãe, de seus irmãos e irmãs?”. Nesta ocasião, ele situa explicitamente a sua ação num vasto projeto que põe as vítimas e seus descendentes no cerne: "apaziguar as dores sempre vivas ao explicar o destino, ao prodigalizar rastros escritos deste destino, ao reintegrar a tragédia individual no drama coletivo; ao permitir à memória perpetuar-se quando os netos e seus descendentes podem e poderão receber as provas documentais da passagem da sua família pelo cataclismo da história que foi a Shoá ${ }^{17 ", .}$

É, aliás, desconcertante constatar quanto o debate extrapolou, desde o início, a esfera arquivístico-histórica, e quanto as tentativas para fazê-lo retornar a ela ao reespecializá-lo ou ao retecnicizá-lo foram votadas ao fracasso. As audições feitas pela CNIL no fim do ano de 1991 sobre a sorte da pasta então provisoriamente depositada nos Arquivos Nacionais são, desse ponto de vista, muito significativas, não fosse pela condição das pessoas ouvidas. Dentre as trinta pessoas entrevistadas, os historiadores são apenas quatro (François Bédarida, Marc Ferro, Pierre Vidal-Naquet e André Kaspi), ao passo que os representantes da comunidade judaica, das igrejas ou dos movimentos dos direitos humanos são majoritários: diretor do Consistório central, secretário do comitê episcopal para as relações com o judaísmo da Igreja Católica, Conselho representativo das instituições judaicas da França, Federação protestante da França, Grande Mesquita de Paris, grande rabino da França, presidente da Liga dos direitos humanos, diretor geral do Fundo social judeu unificado, Associação dos ex-deportados judeus da França, Grande Loja da França, Grande Oriente da França, Liga internacional contra o racismo e o antissemitismo (LICRA). Por um tempo, a lei sobre os arquivos de 1979 recebe uma enorme atenção e, enquanto, na rádio, se pode ouvir o ministro do Meio Ambiente, Brice Lalonde, julgar que seria conveniente queimar os arquivos capazes de ainda prejudicar o futuro $^{18}$, a CNIL dá mostras de uma surpreendente inventividade arquivística

\footnotetext{
${ }^{17}$ KAHN (Annette), Le Fichier, Paris, 1993, p. X.

18 «É preciso atear fogo em tudo isto. », Le Quotidien, 15 de novembro de 1991.
} 
considerando sucessivamente todas as hipóteses quanto à sorte da pasta, incluindo-se as mais irrealistas: anonimização da pasta antes do depósito nos Arquivos Nacionais, depósito puro e simples nos Arquivos Nacionais, manutenção na Secretaria de Estado no Ministério dos Ex-combatentes, dispersão da pasta em outras pastas, como a dos deportados, internados e trabalhadores, depósito no Centro de documentação judia contemporânea (CDJC), depósito nos Arquivos Nacionais e no CDJC, com cópias recíprocas, etc.

\section{Indenizações individuais e historiografia}

Se a questão da pasta judia confirmou a complexidade da relação coletiva com a história da segunda guerra mundial e revelou a intensidade do laço que pode unir indivíduos e documentos de arquivos, a questão da espoliação dos judeus da França e de sua incompleta indenização oferece, numa cronologia significativamente limitada, outra atestação desta configuração ao fornecer o exemplo muito raro, parece-nos, de explosão de um campo historiográfico a partir de uma necessidade ao mesmo tempo de memória e de direito, de natureza individual em todo caso.

Em 1996, uma pesquisa feita por um jornalista sobre a parte sul do Marais, "I'îlot 16", à borda do velho bairro judeu de Paris, suscita escândalo e indignação. Em sua obra Domaine privé, Brigitte Vital-Durand denuncia não somente os abusos que a gestão do domínio privado da cidade de Paris enseja, como acabava de lembrar em junho de 1995 a questão do apartamento colocado à disposição do filho de Alain Juppé com grande vantagem sua, mas também e sobretudo as condições históricas de constituição deste domínio: uma parte proviria de bens judeus confiscados e não restituídos ${ }^{19}$. Em 28 de outubro de 1996, o conselho municipal de Paris decide suspender toda venda de residências enquanto as suas origens não tiverem sido claramente definidas. De maneira concomitante, em 25 de janeiro de 1997, Alain Juppé anuncia, no curso do jantar anual do CRIF, a criação de uma missão de estudos sobre a espoliação dos judeus da França de 1940 a 1944, o decreto de criação que leva a data de 25 de março de 1997. O grande

\footnotetext{
${ }^{19}$ VITAL-DURAND (Brigitte), Domaine privé, Paris, First, 1996, 274 p.
} 
público descobre então a amplitude da espoliação econômica que se abateu sobre os judeus da França durante a segunda guerra mundial e sobretudo os mecanismos de arianização das empresas. Esses processos não eram, certamente, ignorados pelos historiadores, e havia trabalhos sendo executados. Eles não bastaram a dispensar a comissão de se entregar a um verdadeiro trabalho de arquivos e de história, necessário ao cumprimento da sua missão. Na sequência, nota-se um forte crescimento da produção: 110 publicações recenseadas entre 1997 e $2009^{20}$. O impulso dado à pesquisa pela demanda social é aqui incontestável. Os arquivos estiveram no coração deste movimento.

\section{Em direção da história de si}

A ideia de que a guerra e os grandes acontecimentos históricos possam criar problemas psicológicos naqueles que os vivenciaram não é nova. Em linhas gerais, poderse-ia dizer que ela se impõe aos dias seguintes à primeira guerra mundial. A história desta tomada de consciência da alienação da guerra é agora amplamente decifrada pelos historiadores da saída da guerra ${ }^{21}$. A ideia de uma transmissão do trauma e do estresse pós-traumático através das gerações é sem dúvida mais recente e contestada ${ }^{22}$. Françoise Davoine e Jean-Max Gaudillière colocaram no coração de sua prática psicanalista não somente as vítimas da loucura das guerras, mas ainda "os descendentes que ficaram encarregados de transmitir, de geração em geração, pedaços de temporalidade congelados" $^{23}$. O que nos parece mais claramente emergente, pelo menos em termos de tomada de consciência e de teorização, é o próprio local do documento de arquivos e o

\footnotetext{
${ }^{20}$ ANDRIEU (Claire), « Ecrire I'histoire des spoliations antisémites (France, 1940-1944) », Histoire@Politique. Politique, culture, société, nº 9, septembre-décembre 2009.

${ }^{21}$ TISON (Stéphane), Comment sortir de la guerre ? Deuil, mémoire et traumatisme (1870-1940), Rennes, Presses universitaires de Rennes, 2011, $424 \mathrm{p}$.

${ }^{22}$ KAËS (René), FAIMBERG (Haydée), ENRIQUEZ (Micheline), sous la dir., Transmission de la vie psychique entre générations, Paris, Dunod, 2003, VIII-208 p.

${ }^{23}$ DAVOINE (Françoise), GAUDILLIÈRE (Jean-Max), Histoire et trauma. La folie des guerres, Paris, Stock, 2006, p. 41.
} 
surgimento de uma relação específica entre o sujeito e "o arquivo que cura" ${ }^{24}$, em face dos "desmoronamentos do mundo" 25 dos quais escaparam aqueles que sofrem psicologicamente.

\section{Trauma, narrativa de vida e paixão dos arquivos ${ }^{26}$}

Durante quatro anos, a partir de 2002, Yoram Mouchenik, psicólogo clínico, seguiu as atividades da associação Mémoires du convoi n. 6, dedicada à pesquisa dos filhos, famílias, amigos dos deportados do comboio 6 e à transmissão de sua memória ${ }^{27}$. Ele participa das suas reuniões, suas assembleias, suas viagens, suas exposições, suas pesquisas. Formado por crianças escondidas na frança durante a Ocupação, o grupo se constituiu no desejo de honrar e de transmitir a memória de seus pais pela composição de um livro. Na análise à qual ele se entrega sobre o trabalho de luto fundado neste projeto de transmissão, Y. Mouchenik nota várias vezes o lugar da pesquisa do documento de arquivos, apoio, se não principal, pelo menos central das numerosas problemáticas psicológicas que ele encontra e estuda: questão de luto adiado, injunção paradoxal da sepultura apesar da ausência do corpo, filiação e reinscrição em uma cadeia genealógica, apetite insaciável de saber sobre a história de parentes deportados, culpabilidade ligada à sobrevivência, interrogações dos filhos tornados pais em face da necessidade de transmissão de uma história familiar, processos autoterapêuticos para gerir uma infância pilhada. Sem poder seguir sempre o autor até o fim do terreno clínico, não podemos deixar de nos surpreender e nos convencer pela força dos testemunhos recolhidos. Gérard, membro fundador da associação, conheceu seu pai, deportado que retornou dos campos, mas ele sabe pouca coisa de sua história e da de sua família. Foi ele que propôs iniciar pesquisas nos arquivos: "Encontramo-nos num pequeno grupo e a ideia que eu

\footnotetext{
${ }^{24}$ CYRULNIK (Boris), Autobiographie d'un épouvantail, Paris, Odile Jacob, 2008, p. 12-15.

${ }^{25}$ DAVOINE (Françoise), GAUDILLIÈRE (Jean-Max), Histoire et trauma. La folie des guerres, op. cit., p. 31.

${ }^{26}$ " Entre mémoire et histoire, filiation saccagée, trauma, récit de vie et passion des archives », intervenção de Yoram Mouchenik na Conférence internationale supérieure d'archivistique, Paris, 16 de novembro de 2012.

${ }^{27}$ MOUCHENIK (Yoram), « De la disparition au deuil chez les orphelins de la Shoah », L'Autre, 2004, vol. 5, p. 129-141.
} 
tinha tido de ir vasculhar os arquivos lhes interessou. Tornou-se uma espécie de revelação." A frequentação dos arquivos é uma mudança na sua vida e se transforma em imperativo: "A partir do momento em que pus o nariz lá dentro, senti-me dominado por aquilo. É algo que me domina, é algo que eu devo fazer." Como outros membros da associação, ele descreve bem o poder de evocação, de presentificação e de materialização probatória do documento de arquivos: “As palavras, isto basta, é preciso olhar. Isto passa pelo arquivo. Meu avô era mercador de feira. Nos Arquivos Nacionais, eu olho se ele é arianizado e acho seu dossiê, com correspondências em que o administrador provisório insiste muito para ser remunerado. Tu já não estás nas palavras, mas no real, ainda que isto tenha passado, há muito tempo, tu já não estás nos fantasmas e na imaginação. [...] De repente, tu tens sob os olhos elementos materiais que descrevem a trajetória da tua família." 28

A leitura de livros de história poderia ter, por si só, o mesmo efeito de "metabolização da vivência traumática" e "de reordenamento da sucessão das gerações" ${ }^{30}$ ? Provavelmente não. O processo de historicização do qual se trata não é verdadeiramente da história, ou pelo menos não é da história no sentido de discurso científico fundado na análise das forças sociais e visando o estabelecimento de uma forma de compreensão do passado em progresso constante. Trata-se antes da elaboração de uma narrativa de vida que permite uma reconfiguração do eu, "de uma narrativização por adultos de uma vivência infantil trágica cujas sequelas traumáticas continuam fazendo-se ouvir"31. A mobilização ou a acumulação das lembranças biográficas é aqui claramente finalizada como uma maneira do "agir memorial" visando uma "reinscrição" na história de sua família e de seu grupo social ${ }^{32}$. Certamente, todas as trajetórias individuais são possíveis e não é raro que verdadeiros perfis "de arquivistas-

\footnotetext{
${ }^{28}$ MOUCHENIK (Yoram), « Ce n'est qu'un nom sur une liste, mais c'est mon cimetière ». Traumas, deuils et transmission, chez les enfants juifs cachés en France pendant l'Occupation, Paris, La Pensée sauvage, 2006, p. $153-157$.

${ }^{29}$ MOUCHENIK (Yoram), « Ce n'est qu'un nom sur une liste, mais c'est mon cimetière »..., op. cit., p. 127.

${ }^{30}$ MOUCHENIK (Yoram), « Ce n'est qu'un nom sur une liste, mais c'est mon cimetière »..., op. cit., p. 169.

${ }^{31}$ MOUCHENIK (Yoram), «Ce n'est qu'un nom sur une liste, mais c'est mon cimetière »..., op. cit., p. 26.

32 LEMÉE-GONÇALVES (Carole), Daniel Galay (Daniel), « L'Après-Shoah : des traumas aux processus de réinscription », Face à face, regards sur la santé, 2003, n 5, p. 83-96.
} 
historiadores" emerjam ${ }^{33}$. Às vezes, por acaso ou necessidade, aquele que pesquisa é historiador profissional; ele pretende até mesmo fazer de sua pesquisa um livro de história. Entre carga emocional e necessidade científica, toca-se o último dos procedimentos e então, mas somente então, é o trabalho histórico que se reveste de uma dimensão terapêutica. Pensamos em Ivan Jablonka e em seu trabalho realizado para obter a habilitação para orientar pesquisas sobre seus avós, Matès e Idesa, judeus comunistas refugiados na França em 1937, mortos em deportação em 1943. Acreditou-se na importância da obra. Viu-se quanto, de passagem, o documentos de arquivos aí está instalado numa condição diferente daquela, tradicional, da fonte histórica: "Eu o tenho sob os olhos, este registro de encarceramento exumado dos Arquivos do Departamento de Polícia, intitulado "Via pública-Estrangeiros" e eu os vejo, "Feder Idesa, rua do Pressoir, 11, recusa de estada" e "Jablonka Matès, idem" embaixo das páginas 390-391 [...], eu os vejo e sinto o seu medo. [...] Eu vou ao encontro de meu pai, numa manhã, nos Arquivos da cidade de Paris, perto da porta dos Lilás. [...] Passamos em seguida ao registro da $16^{\mathrm{a}}$ câmara do tribunal correcional do Sena. Nós folheamos as páginas febrilmente. Emoção: ele está aqui". ${ }^{34}$

\section{Novos usos dos arquivos}

Esta abordagem emocionalmente individualizada do documento de arquivos continua difícil de definir quantitativamente: nas salas de leitura dos serviços de arquivos nada distingue o leitor historiador do leitor em busca de sua história, e as categorias do formulário de inscrição nos serviços públicos de arquivos que convidam o usuário a se identificar como genealogista, cientista ou usuário que efetua pesquisas de caráter administrativo ou jurídico não ajudam muito. Alguns indícios podem, contudo, ser reunidos quanto à dispersão deste tipo de comportamento.

Sobretudo na internet, listas de divulgação, grupos de discussão, blogs, contas do twitter e sites familiares são um lugar privilegiado para o compartilhamento dos

\footnotetext{
${ }^{33}$ MOUCHENIK (Yoram), « Ce n'est qu'un nom sur une liste, mais c'est mon cimetière »..., op. cit., p. 25.

34 JABLONKA (Ivan), Histoire des grands-parents que je n'ai pas eus : une enquête, Paris, Seuil, 2012, p. 163.
} 
documentos de arquivos para todos aqueles que procuram forjar sua compreensão de um "pedaço da história escapado da História"35. "Yahoo group France" alberga todo um leque de grupos de discussão que toca diversos aspectos da segunda guerra mundial e que reservam um lugar particular aos documentos de arquivos, quer sejam escritos, quer sejam iconográficos. O grupo "Stalag" reúne um conjunto de outros grupos que se dedicam aos campos de prisioneiros durante a segunda guerra mundial. ${ }^{36}$ Os membros, frequentemente descendentes de prisioneiros, trocam informações sobre os serviços de arquivos, conselhos de pesquisa, listas de prisioneiros, documentos, fotografias. Fundado em abril de 2007, ele reúne hoje 1.200 membros. Sozinho, o grupo Stalag $1 \mathrm{~A}$ (Stalags da Prússia Oriental), reivindica 65.000 visitas desde a sua fundação em $2007^{37}$. Alguns grupos mostram um posicionamento militante, em reação a uma escrita da história denunciada como oficial demais. O grupo "Ardennais refugiés" pretende facilitar os intercâmbios entre todos os evacuados coletando as "narrativas, anedotas e fotos que permitam a cada um encontrar seus ancestrais e identificar os locais de exílio" a fim de que esta "parte do patrimônio familiar" seja melhor conhecida. ${ }^{38}$ "Vítimas da guerra de 39-45, as vítimas e seus percursos" é dedicado a "todas as pessoas que desejem testemunhar ou efetuar pesquisas sobre os trabalhadores forçados em país inimigo, as pessoas civis internadas, deportadas, denunciadas..." 39 . Aberto em outubro de 2007, o grupo recebe principalmente as demandas de informação de descendentes preocupados em fazer "seu dever de memória": "Eu me apresento, sou belga, casado e pai de três filhos. Acabo de descobrir velhas fotos de cativeiro de meu avô Modeste Dejong, nascido em 24/08/1908 em Hodimont (Verviers) e morto em 25/02/1987. Sendo o assunto do seu cativeiro tabu em casa, não tenho senão poucas informações, mas talvez um de vocês possa substanciar meus dados. [...] Meu objetivo é tentar encontrar o que ele pôde viver e fazer disso um

\footnotetext{
35 DAVOINE (Françoise), GAUDILLIÈRE (Jean-Max), Histoire et trauma. La folie des guerres, op. cit., p. 37.

${ }^{36}$ [On-line], disponível em http://fr.groups.yahoo.com/group/stalag/ (consultado em 14 de março de 2013).

${ }^{37}$ [On-line], disponível em http://fr.groups.yahoo.com/group/Stalag_PO (consultado em 14 de março de 2013).

${ }^{38}$ [On-line], disponível em http://fr.groups.yahoo.com/group/ardennaisrefugies/ (consultado em 14 de março de 2013).

39 [On-line], disponível em http://fr.groups.yahoo.com/group/Victimes-Guerre-39_45/ (consultado em 14 de março de 2013).
} 
dever de memória para seus bisnetos"40. As histórias familiares marcadas pela Shoá podem dar ensejo à criação de sites familiares reservados ao núcleo familiar. "Elie e Pierre Feifer" criado em 2006 não reúne senão nove membros. Ele reivindica para si a tradição judaica do livro da lembrança (yisker-buch) e quer "ligar os vivos aos mortos na continuidade não ininterrupta do tempo", tendo seus autores consciência de sua responsabilidade de "transmissores provisórios de testemunhos familiares transmitidos a outros" ${ }^{41}$.

As exposições de arquivos são outro lugar propício à exploração do diálogo entre documentos da segunda guerra mundial e públicos que não são exclusivamente movidos pela vontade de fazer história, mas pelo desejo de aprender e de compreender em família. Os estudos por questionário ou entrevistas com visitantes são raros nas exposições de arquivos. As notas e comentários deixados nos livros de visitas postos à disposição dos visitantes são outra via de aproximação. Um estudo feito na exposição 1942 en Anjou proposto pelos arquivos do Departamento de Maine-et-Loire de setembro a janeiro de 2013 confirma a pregnância de uma relação individualizada e afetiva com os documentos de arquivos ${ }^{42}$. Enquanto os que conceberam a exposição pretendiam, pelo menos a crer na sua comunicação escrita acerca do projeto, limitar-se a um discurso essencialmente histórico ${ }^{43}$, os visitantes se apropriam dela na medida da sua história pessoal e insistem no poder emocional dos documentos expostos: "Obrigado por esta exposição, particularmente emocionante para um homenzinho que tinha 6 anos em 42, e “que, sobretudo, não devia nada a ninguém!” (eu era filho de um professor destituído por ser francomaçon). É assim que eu me revejo hoje...”; “Eu tinha 9 anos em 1942! Eu me

\footnotetext{
${ }^{40}$ [On-line], disponível em http://fr.groups.yahoo.com/group/Victimes-Guerre-39_45/message/46 (consultado em 14 de março de 2013).

${ }^{41}$ [On-line], disponível em http://fr.groups.yahoo.com/group/Elie_Et_Pierre_Feifer/ (consultado em 14 de março de 2013).

${ }^{42}$ BROCHET (Hugues), CORMIER (Maxime), COUPEVENT (Guillaume), GUÉRINES (Côme de), MASSARD (Nicolas), PERRAULT (Lucie), RUCHAUD (Camille), RULLIER (Benjamin), VALENCIA (Océane), « Les publics des expositions des archives départementales de Maine-et-Loire ", Les expositions d'archives et leurs publics. Bilan, mutations, prospectives, Angers, Journée d'étude du 15 février 2013 organisée par les étudiants du master métiers des archives, a ser publicado, relato on-line disponível em http://alma.hypotheses.org/722 (consultado em 15 de março de 2013).

${ }^{43}$ [On-line], disponível em www.cg49.fr/no_cache/haut/espace.../dossiers-de-presse/?cid. (consultado em 14 de março de 2013).
} 
lembro... os invernos frios... as lesões por causa do frio... Eu vim hoje com o meu neto!"; “A exposição nos mostra concretamente o que aprendemos. É emocionante! O nome de meu pai deve estar no registro do Pré-Pigeon 44!"; "Obrigado por esta exposição! O ano do meu nascimento. Minha pequena história precisa da grande história vivida aqui e em toda a França”; “A emoção que me tomou não me permitiu escrever imediatamente!”

\section{Tomadas de consciência e adaptações}

Essas evoluções das lógicas de uso ${ }^{45}$ são percebidas pelos arquivistas e por todos os profissionais que têm ligação com os arquivos. Eles são obrigados a inventar novas formas de recepção dos públicos e de acompanhamento dos caminhos pessoais, às vezes dolorosos, induzidos pelo encontro com o documento de arquivos. Desde seu primeiro relatório de atividade em 2001, a CIVE descreve a necessidade "de escuta e de humanidade" ${ }^{46}$ dos requerentes, o que a leva a estruturar uma "célula de recepção e de assistência" cujas missões são formalizadas em 2002 em torno do apoio psicológico" em face de percursos pessoais trágicos" 47 . O acompanhamento não é apenas em relação à instrução administrativa da pasta dos requerentes ou a decifração das sessões da comissão, mas também sobre a comunicação midiatizada dos documentos de arquivos reunidos ao longo do procedimento. Simetricamente, são igualmente as demandas de informação e de consultas ligadas às espoliações e à segunda guerra mundial que levam à abertura em janeiro de 2004 de um escritório de pesquisas administrativas familiares no seio do departamento da comunicação dos documentos do Centro Histórico dos Arquivos Nacionais (CHAN). Se a descrição das missões desta nova célula administrativa insiste principalmente nas necessidades de orientação dos leitores, no encurtamento dos

\footnotetext{
${ }^{44}$ Prisão de Angers.

45 POISSENOT (Claude), RANJARD (Sophie), Usages des bibliothèques, approche sociologique et méthodologie d'enquête, Villeurbanne, Presses de l'ENSSIB, 2005, p. 248 e seguintes.

${ }^{46}$ Comissão para a indenização das vítimas de espoliações havidas em razão das legislações antissemitas em vigor durante a Ocupação, Relatório de atividades da comissão apresentado ao Primeiro Ministro, Paris, 2001, p. 16.

${ }^{47}$ Comissão para a indenização das vítimas de espoliações havidas em razão das legislações antissemitas em vigor durante a Ocupação, Relatório de atividades da comissão apresentado ao Primeiro Ministro, Paris, 2002, p. 5 .
} 
tempos de respostas e na necessidade de coordenar os esforços dos diferentes serviços de arquivos envolvidos ${ }^{48}$, é ao mesmo tempo a questão do acompanhamento individualizado de usuários que não têm como única característica serem inexperientes em pesquisa nos arquivos, mas que estão diretamente envolvidos pelos documentos que eles demandam, que irrompe na prática dos arquivistas. O escritório das pesquisas administrativas familiares dos Arquivos Nacionais inspira-se no "escritório cidadão" dos arquivos do Departamento do Aude, fórmula igualmente retomada pelos arquivos do Departamento do Hérault, que, desde sua instalação nos prédios de Pedras vivas, a Cidade dos saberes e do esporte para todos, dispõe de um espaço contíguo à sala de leitura "reservado à recepção, por agendamento, de pessoas cujas pesquisas demandam um acompanhamento personalizado" ${ }^{49}$. Nesses dois casos, o objetivo ultrapassa claramente os arquivos da segunda guerra mundial.

Não é menos significativo constatar que foi sua experiência como responsável por este escritório que inspirou à arquivista Caroline Piketty um livro de tom pessoal inédito entre os arquivistas: "Je cherche les traces de ma mère", chronique des archives, publicado em 2006. Conhece-se o sucesso que esta obra obteve, traduzido em alemão desde $2007^{50}$, que inspirou, por exemplo, um episódio das Éphémères, espetáculo proposto por Ariane Mnouchkine e o Théatre du soleil ${ }^{51}$. Montado em Cartoucherie em 2006, ele reuniou mais de 14.000 espectadores ao longo de uma turnê nacional e internacional em 2007 e 2008. Vemos aí uma funcionária dos arquivos receber, no meio das caixas, uma mulher que procura compreender a história de sua mãe, filha de deportados. A cena acontece numa obra inteiramente dedicada às pequenas histórias, às origens, às lembranças e à sua relação com a vivência e o passado coletivos. Haveria todo um estudo a ser feito sobre a recepção do livro de Caroline Piketty. Para os arquivistas, é

\footnotetext{
${ }^{48}$ PIKETTY (Caroline), Recherches administratives et familiales au Centre historique des Archives nationales, Paris, janeiro de 2005, [on-line], disponível em http://www.archivesnationales.culture.gouv.fr/chan/chan/pdf/Panneau\%20d\%27lnfo\%20BRAF-f\%E9v20051.pdf (consultado em 15 de março de 2013).

${ }^{49}$ [On-line], disponível em http://pierresvives.herault.fr/ressource/bureau-citoyen (consultado em 15 de março de 2013).

${ }^{50}$ Ich suche die Spuren meiner Mutter.

51 «Aux archives », episódio 15 da segunda temporada de Éphémères.
} 
certo que ele é um marco. É a primeira vez que uma arquivista toma a palavra para falar de sua experiência profissional, o que não é tão frequente, de uma maneira que não é nem histórica nem arquivística, mas inteiramente afetiva. Não que até então os arquivistas nunca tenham sentido constrangimento ou compaixão em face dos retalhos de vidas que eles eram levados a conhecer, mas esses momnetos tinham sido calados desde então. É o peso da experiência, e sua reiteração, que liberou a palavra. Evocando as fichas anônimas das crianças internadas em Drancy, pequenas demais para saberem seus nomes, a autora confessa sua vontade de se "lavar para tentar dissipar o abominável" 52 . Ela toca com o dedo a força insustentável do documento de arquivos, ao ponto de às vezes interromper a leitura dos originais para propor o envio postal de fotocópias: "Não desejei vê-los prolongar sua leitura no meu escritório, sabendo quanto ela era carregada de significado, e Ihes propus fazer chegar a eles a fotocópia integral desses documentos." 53 Ela sente que a sua concepção da profissão transforma e que seu papel se afasta dos limites seguros da técnica arquivística e da história: “Do terapeuta, eu me aproximo sem estar verdadeiramente certa de saber tratar as feridas muito profundas. Eu franqueio as passarelas, carregada das questões que me foram colocadas, aliviando um pouco aqueles que mas colocam convidando-os a passar o vau."54 O choque de profissionalismo é que ele autoriza, pelo menos em pensamento, todas as transgressões: “Tenho uma ternura particular e culpável pelas famílias dos espoliados. Se por acaso um dentre eles estivesse a ponto de levar uma foto, uma carta manuscrita ou um documento de identidade de seu pai ou de sua mãe, eu confesso que entenderia." 55

"O morto agarra o vivo": este adágio medieval servia a exprimir a instantaneidade da devolução sucessória e significar que o direito de sucessão dos bens do defunto é adquirido no mesmo dia da morte por seu herdeiro. Pierre Bourdieu o havia modificado em seu proveito para expor suas concepções das relações da história e da

\footnotetext{
${ }^{52}$ Caroline Piketty, « Je cherche les traces de ma mère ». Chronique des archives, Paris, Autrement, 2006, p. 106.

${ }^{53}$ Caroline Piketty, « Je cherche les traces de ma mère ». Chronique des archives, Paris, Autrement, 2006, p. 81.

${ }^{54}$ Caroline Piketty, « Je cherche les traces de ma mère ». Chronique des archives, Paris, Autrement, 2006, p. 102.

${ }^{55}$ Caroline Piketty, " Je cherche les traces de ma mère ». Chronique des archives, Paris, Autrement, 2006, p. 100.
} 
sociologia ${ }^{56}$. "O arquivo agarra o vivo", seríamos tentados a dizer tomando também grandes liberdades em relação ao sentido original da máxima jurídica. Nenhuma imediatidade obrigada no processo que põe em relação os descendentes de um deportado, de um prisioneiro, de um refugiado, de um resistente ou de um colaborador, com os arquivos que guardam rastros de seus percursos. O reencontro se faz segundo uma temporalidade aleatória, na qual, contudo, a morte de um pai ou avô não fica sem desempenhar um papel. É de um "agarramento" que se trata, por outro lado, em todos os sentidos do termo: a apropriação do evento histórico pelo romance familiar passa necessariamente pelo encontro com o documento de arquivos que revela então todo o seu poder agindo sem escapatória possível. Observável a propósito dos arquivos da segunda guerra mundial e das lógicas de uso que eles suscitam em grande escala nos anos 1990, esta orientação individualizada da relação com os arquivos não é, contudo, específica deste período histórico. Muito ao contrário, a demanda dirigida aos arquivos da segunda guerra mundial prefigura, ou simplesmente traduz um vasto movimento de relativização das solicitações puramente históricas do material arquivístico em proveito das estratégias de pesquisa de si e de construção da individualidade ${ }^{57}$.

\footnotetext{
${ }^{56}$ BOURDIEU (Pierre), « Le mort saisit le vif. Les relations entre l'histoire réifiée et l'histoire incorporée », Actes de la recherche en sciences sociales, 1980, vol. 32, $n^{\text {os }} 32-33$, p. 3-14.

${ }^{57}$ MARCILLOUX (Patrice), Les Ego-archives. Traces documentaires et recherches de soi, Rennes, Presses universitaires de Rennes, 2013.
} 
Universidade do Estado de Santa Catarina - UDESC

Programa de Pós-Graduação em História - PPGH

Revista Tempo e Argumento

Volume 05 - Número 09 - Ano 2013

tempoeargumento@gmail.com 